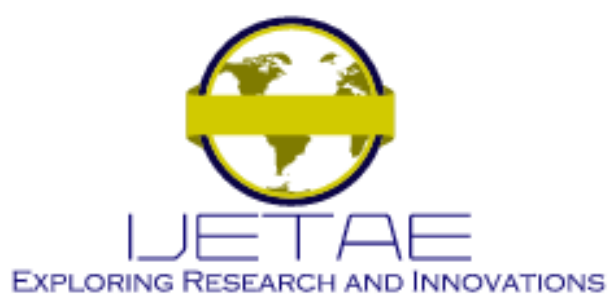

International Journal of Emerging Technology and Advanced Engineering

Website: www.ijetae.com (E-ISSN 2250-2459, Scopus Indexed, ISO 9001:2008 Certified Journal, Volume 11, Issue 07, July 2021)

Manuscript Received: 29 May 2021, Received in Revised form: 09 July 2021, Accepted: 14 July 2021 DOI: 10.46338/ijetae0721_06

\title{
The Definition of the Paramethers of Superconducting Film for Production of Protection Equipment Against Electromagnetic Environmental Effects
}

\author{
NataliiaYeromina ${ }^{1}$, Ivan Kravchenko ${ }^{2}$, Igor Kobzev ${ }^{3}$, Maksym Volk $^{4}$, Viktor Borysenko ${ }^{5}$, Viktoriia Lukyanova ${ }^{6}$, \\ Yurii Gnusov ${ }^{7}$, Yurii Horelov ${ }^{8}$, Oleh Rikunov ${ }^{9}$, Sergiy Kaplun ${ }^{10}$ \\ 1,4,5 Department of Electronic Computers, Kharkiv National University of Radio Electronics, Ukraine, Kharkiv, 61000 \\ ${ }^{2}$ Department of Fundamental disciplines and radio engineering of Ivan Kozhedub Kharkiv National Air Force University, \\ Ukraine, Kharkiv, 61023 \\ ${ }^{3}$ Department of Information Technologies and Control System Educational and Research Institute of Public Administration of \\ Kharkiv National University named after VN Karazina, Ukraine, Kharkiv, 61050 \\ ${ }^{6}$ Department of Natural Sciences, Kharkiv National University of Radio Electronics, Ukraine, Kharkiv, 61166 \\ ${ }^{7,8}$ Kharkiv National University of Internal Affairs, Kharkiv, Ukraine, 61080 \\ ${ }^{9,10}$ Department of Technical and Logistics Support, National Academy of the National Guard of Ukraine, Ukraine,
} Kharkiv, 61001

\begin{abstract}
The paper presents the results of evaluating the propagation of a plane electromagnetic wave (EMW) over the surface of a film made of a high-temperature superconductor (HTS) in both superconducting $S$ and normal $N$ states, as well as an analysis of the parameters of a thin HTS film necessary for implementing a device for protection against electromagnetic radiation. Evaluation of the propagation of EMW over the surface of a thin HTS film was performed on the basis of a two-fluid model. As a result of the research, relations were obtained for determining the value of the surface impedance and the depth of penetration of EMW into a superconducting film in $S$ and $N$ states. It is shown that the expression for determining the penetration depth of EMW into a superconducting film in the normal $\mathbf{N}$ state is applicable provided that the frequency of the signal field does not exceed the critical value, which is determined by the binding energy of charge carriers at a temperature not exceeding the transition temperature to the superconducting state. Based on the relations for determining the surface impedance of a thin HTS film, relations are obtained for the active surface resistance, which is the real part of the surface impedance, and the surface reactance, which is its imaginary part, in the superconducting and normal states. Using these ratios, the quality parameter of the HTS thin film is introduced. The dependence of the quality factor of the HTS film on its thickness is found. It is shown that the highest value of the quality factor is realized when the film thickness is less than or of the order of the penetration depth. It is noted that this dependence is valid only if the film thickness does not depend on its quality.
\end{abstract}

Keywords - superconducting film, electromagnetic wave, two-fluid model, surface impedance, penetration depth.

\section{INTRODUCTION}

The intensive development and application of powerful generation systems makes it necessary to find the most effective means of protecting telecommunication, communication and navigation systems, ground survey systems that may be disrupted by high-intensity electromagnetic pulse radiation (EMR) and ultra-short pulse duration [1]. In the articles [2,3] the ways and means of protection of radio-electronic devices based on the application of construction materials and nature-like technologies are considered. The articles $[4,5]$ on highspeed protective devices discuss the use of thin superconducting films. The construction of protective devices based on high-temperature superconductors (HTS) depends on the possibility of carrying out reversible S-N phase transitions therein. A typical representative of HTS is the yba2cu3o7-x compound, which is a type II superconductor. In such HTS, the surface energy at the edge between superconducting and normal phases is negative when forming a normal area in superconducting state. This results in the instability of the type II superconductors in relation to the formation of vortices (Abrikosov vortices), each of which carries a magnetic flux quantum. 


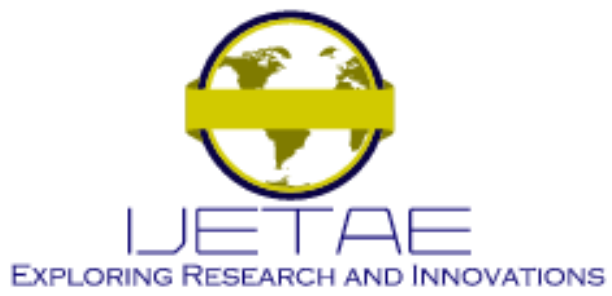

International Journal of Emerging Technology and Advanced Engineering

Website: www.ijetae.com (E-ISSN 2250-2459, Scopus Indexed, ISO 9001:2008 Certified Journal, Volume 11, Issue 07, July 2021)

Instability occurs in the lower critical field, where vortices are considered at distances of the depth of penetration of the field into the superconductor. When the normal areas of vortices are closed, the superconducting state is destroyed. External inputs may disrupt the superconductivity of the HTS and consequently the state of normal regions. Thus, the determination of the appropriateness of using HTS for the creation of devices for the protection of radio electronic means against pulsed EMR makes it necessary to carry out studies aimed at studying the destruction of superconducting state under external influences, as well as definition of parameters of superconducting film at which switch conditions will be implemented.

\section{AnAlysis Of Literature DAta And Problem STATEMENT}

The article [6] considers the use of HTS as adjustable filters under the influence of an electric field. The authors limited themselves to studying the frequency properties of such filters. In particular, they showed that with a DC voltage bias, it is possible to provide filter tuning at about $2.5 \mathrm{GHz}$ with a bandwidth of less than $2 \%$ and more than $15 \%$ of the adaptive range. The change in the state of superconductivity under external influence was not considered in the work.

The article [7] shows the possibility of creating controllable filters and amplifiers, the design of which includes a thin HTS film in a mixed state. Amplification of EMW occurs as a result of the interaction of a wave with a magnetic vortex grid moving in the superconductor film. Attenuation or amplification is controlled by changing the magnetic field. However, the implementation of EMR protection devices is not affected. HTS applications for narrowband filters and resonators have been studied in a number of papers [8-11].

In [8], based on the method of moments, a technique for designing a filter with a fractional passband of $2.27 \%$ at a frequency of $883.0 \mathrm{MHz}$ is proposed. The filter is made using thin films of thallium-barium-calcium-copper oxide on a two-inch plate of lanthanum aluminate (LaAlO3). The $\mathrm{S}$-parameters of the filter are investigated, good agreement with the simulation results is shown. The use of superconducting thin films based on $\mathrm{LaAlO} 3$ in protective devices was not considered in this work. In [9], the results of studies of 10-pole microstrip bandpass filters with a central frequency of $1.75 \mathrm{GHz}$ are presented.
The high performance of the filter with an insertion loss of no more than $0.5 \mathrm{~dB}$ and the ability to control the power up to $10 \mathrm{~W}$ of the input power at $\mathrm{T}=60 \mathrm{~K}$ is shown. The possibility of changing the state of superconductivity of a microstrip line under the influence of an external electromagnetic field has not been studied.

In [10], intermodulation distortions were investigated when signals are applied at more than one frequency. In [11], the results of studies of the design and operational characteristics of coplanar waveguide microwave filters using superconducting films are presented. The results of experimental studies of a prototype of a miniature $\mathrm{CPW}$ filter with its simulated characteristics are presented.

In [12], the results of the development of a hightemperature superconducting receiving filter with a narrow passband characteristic of a $9 \mathrm{GHz}$ weather radar are presented to reduce interference between adjacent radar channels. To suppress radiation losses and achieve a high Q-factor, coupled microstrip linear resonators with a wavelength of 1.5 times and a resonant frequency of an odd mode were used. The frequency response of the filter at the center frequency of $9700 \mathrm{MHz}$ has an insertion loss of 1.8 $\mathrm{dB}$, which is consistent with the design specifications. The use of HTS for the implementation of the protection device has not been considered.

In [13], the design and modeling of the UWB filter characteristics are considered. The proposed UWB filter provides huge bandwidth from $2.5 \mathrm{GHz}$ to $8 \mathrm{GHz}$. Filter estimation parameters such as return loss, insertion loss, phase and group delay are obtained and their responses analyzed. The filter return loss (S11) and insertion loss (S21) are shown to be $-40 \mathrm{~dB}$ and $-1 \mathrm{~dB}$, respectively. The use of an EMR filter has not been considered.

In [14], a compact coplanar waveguide dual-band hightemperature superconducting band-pass filter with a dummy short-circuited ring resonator (SC-SLRR) is presented. The relationship between the parameters of electrical length and resonance characteristics is shown. The authors limited themselves to studying only the frequency properties of the filter.

In [15], a compact band-pass filter based on multimodal coplanar waveguide resonators implemented using a slowwave periodic structure is presented. A multimodal circuit model of the filter is proposed and experimentally confirmed. A prototype second order filter at $1.9 \mathrm{GHz}$ with a compact size of $0.31 \lambda \mathrm{g} \times 0.19 \lambda \mathrm{g}$ was developed and manufactured. The filter has measured fractional passbands of $9.3 \%$ and $3.7 \%$ for rejection levels of 20 and $30 \mathrm{~dB}$, respectively, and $1.3 \mathrm{~dB}$ insertion loss in passband. 


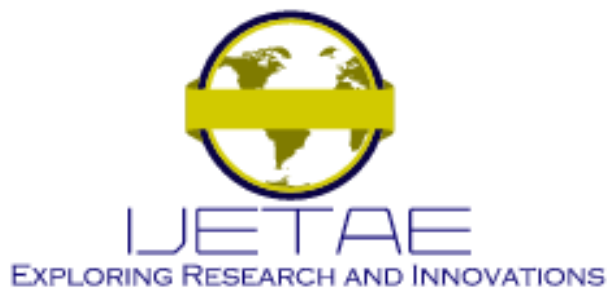

International Journal of Emerging Technology and Advanced Engineering

Website: www.ijetae.com (E-ISSN 2250-2459, Scopus Indexed, ISO 9001:2008 Certified Journal, Volume 11, Issue 07, July 2021)

Geometric models of broadband circuits for various configurations of a loaded slot line and loaded coplanar waveguide (CPW) are presented in [16]. Also presented are three applications, the design of which is based on the proposed modeling methodology. It is a maximally flat third-order low-pass filter with a cutoff frequency of 1.4 $\mathrm{GHz}$, a slow-wave structure of $3 \mathrm{GHz}$ with a slow-wave ratio greater than 2 in the linear range of the dispersion ratio, and a balanced composite right / left SRR-loaded CPW with $100 \%(2.31-7,1 \mathrm{GHz})$ fractional bandwidth.

The paper [17] suggests an electrodynamic model describing the dispersion properties of the magnetostatic surface wave in the structure of the ferrite/superconductor, on the basis of which the surface resistance of the superconducting film in the magnetic field is determined. However, the destruction of the superconducting state by EMW propagating along the HTS has not been investigated. The work [18] contains the results of the analysis of the frequency dependence of the penetration depth of the magnetic field into the conductor, assuming that the pseudo-alkali phase is related to the charge density waves. The dissemination of EMW along the HTS was not addressed. Also, changes in surface resistance due to EMW exposure were not estimated. Thus, in the well-known studies of the use of HTS in the creation of microwave components, the study of the destruction of superconducting states under external influences, as well as the determination of superconducting film parameters, where switching conditions will be implemented has not been properly developed.

The aim of the article is to determine the conditions for the transition of a thin HTS film from the superconducting state to the normal state under external influence, as well as the parameters of the superconducting film under which the switching conditions will be realized.

In order to achieve the object of the research, the following tasks have to be accomplished.

1. Estimate the effect of EMW propagating over the surface of a thin HTS film on its transition from a superconducting state to a normal state.

2. Perform an analysis of the HTS parameters necessary for the implementation of the EMR protection device.

\section{MAIN MATERIAL}

1) Evaluation of the effect of EMW spreading over the surface of the thin HTS on its transition from a superconducting state to a normal state.

If an EMW propagates in a dielectric and falls on the surface of a superconducting film in the $\mathrm{S}$ or $\mathrm{N}$ state, the wave reflectance will be close to 1 [19] with the electromagnetic field of the wave partially penetrating the conductor, and some of the energy turns to heat. The penetration depth of the magnetic field into the superconductor and the surface impedance are quantitative characteristics that describe the phenomena occurring in the superconducting strip.

Most commonly, when solving the problems of technical electrodynamics, HTS is considered as the ideal conductor. In this case the penetration depth and the surface impedance are zero, the incident wave is reflected completely, the field is not penetrated into the conductor, the energy of the wave is not absorbed. However, no perfect conductors exist. It is known that as the frequency of the electromagnetic field increases, the penetration depth and surface impedance increase. Therefore, in order to create a protective device based on HTS, we shall carry out a study of the spread of a flat electromagnetic wave over the surface of a film made of HTS, both in the S and N states.

The penetration of the electromagnetic wave into the HTS film located on the dielectric substrate is considered on the basis of the two-fluid model [20]. The essence of the model is that all charge carriers in the material are divided into two groups: charge carriers in a normal state with $n_{N}$ concentration, and charge carriers in a superconducting state with $\mathrm{n}_{\mathrm{S}}$ concentration.

The total concentration of charge carriers $n$ equals to:

$$
\mathrm{n}=\mathrm{n}_{\mathrm{S}}+\mathrm{n}_{\mathrm{n}} .
$$

Let's suppose a time-variable electric field with tension $\overline{\mathrm{E}}$ in a superconductor.

Then for superconducting film in superconducting state, let's form first London equation [20]:

$$
\frac{\partial \overline{\mathrm{j}}_{\mathrm{S}}}{\partial \mathrm{t}}=\frac{1}{\Lambda} \overline{\mathrm{E}}
$$




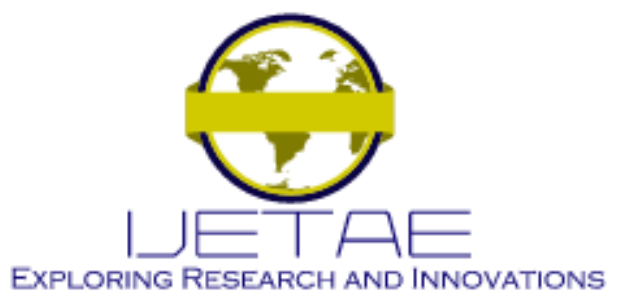

International Journal of Emerging Technology and Advanced Engineering

Website: www.ijetae.com (E-ISSN 2250-2459, Scopus Indexed, ISO 9001:2008 Certified Journal, Volume 11, Issue 07, July 2021)

where $\Lambda=\frac{m_{\mathrm{S}}}{\mathrm{n}_{\mathrm{s}} \mathrm{e}^{2}}$,

$\mathrm{m}_{\mathrm{S}}$ - effective mass of superconducting charge carriers;

$\mathrm{n}_{\mathrm{s}}$ - superconducting electron concentration;

e - electron charge.

According to the two-fluid model, the current density of the superconducting charge carriers is related to their motion speed.

Therefore, equation (2) can be rewritten as:

$$
\overline{\mathrm{j}}_{\mathrm{S}}=\mathrm{en}_{\mathrm{S}} \overline{\mathrm{v}}_{\mathrm{S}}
$$

where $\frac{\partial \overline{\mathrm{v}}_{\mathrm{S}}}{\partial \mathrm{t}}=\frac{\mathrm{e}}{\mathrm{m}_{\mathrm{S}}} \overline{\mathrm{E}}$

To determine the current density, let's record the expression for the speed of superconducting charge carriers and the first Maxwell's equations:

$$
\left\{\begin{array}{l}
\frac{\partial \overline{\mathrm{v}}_{\mathrm{S}}}{\partial \mathrm{t}}=\frac{\mathrm{e}}{\mathrm{m}_{\mathrm{S}}} \overline{\mathrm{E}}, \\
\operatorname{rot} \overline{\mathrm{H}}=\sigma_{\mathrm{N}} \overline{\mathrm{E}}
\end{array}\right.
$$

where $\sigma_{\mathrm{N}}$ is the specific conductivity of the HTS in the N-state.

The density of current flowing through the superconducting film is known to vary mainly with respect to the width of the strip.

Then equations (4) in the rectangular reference system (fig. 1) can be written as follows:

$$
\left\{\begin{array}{l}
\frac{\partial \mathrm{v}_{\mathrm{S}_{\mathrm{x}}}}{\partial \mathrm{t}}=\frac{\mathrm{e}}{\mathrm{m}_{\mathrm{s}}} \mathrm{E}_{\mathrm{x}}, \\
\frac{\partial \mathrm{H}_{\mathrm{z}}}{\partial \mathrm{y}}-\frac{\partial \mathrm{H}_{\mathrm{y}}}{\partial \mathrm{z}}=\sigma_{\mathrm{N}} \mathrm{E}_{\mathrm{x}}, \\
\frac{\partial \mathrm{H}_{\mathrm{x}}}{\partial \mathrm{z}}-\frac{\partial \mathrm{H}_{\mathrm{z}}}{\partial \mathrm{y}}=\sigma_{\mathrm{N}} \mathrm{E}_{\mathrm{y}}, \\
\frac{\partial \mathrm{H}_{\mathrm{y}}}{\partial \mathrm{x}}-\frac{\partial \mathrm{H}_{\mathrm{x}}}{\partial \mathrm{y}}=\sigma_{\mathrm{N}} \mathrm{E}_{\mathrm{z}}
\end{array}\right.
$$

For a flat electromagnetic wave $\overline{\mathrm{E}}$ and $\overline{\mathrm{H}}$ don't depend on $\mathrm{x}$ and $\mathrm{y}$ (see fig. 1), but only on $\mathrm{z}$ and $\mathrm{t}$.
Therefore, $\frac{\partial \mathrm{H}}{\partial \mathrm{x}}=0 \frac{\partial \mathrm{H}}{\partial \mathrm{y}}=0 \mathrm{H}_{\mathrm{x}}=0$

Then equations (5) can be rewritten as:

$$
\left\{\begin{array}{l}
\frac{\partial \mathrm{v}_{\mathrm{s}_{\mathrm{x}}}}{\partial \mathrm{t}}=\frac{\mathrm{e}}{\mathrm{m}_{\mathrm{S}}} \mathrm{E}_{\mathrm{x}}, \\
\frac{\partial \mathrm{H}_{\mathrm{y}}}{\partial \mathrm{z}}=\sigma_{\mathrm{N}} \mathrm{E}_{\mathrm{x}} .
\end{array}\right.
$$

or

$$
-\frac{\mathrm{e}}{\mathrm{m}_{\mathrm{S}} \sigma_{\mathrm{N}}} \frac{\partial \mathrm{H}_{\mathrm{y}}}{\partial \mathrm{z}}=\frac{\partial \mathrm{v}_{\mathrm{S}_{\mathrm{x}}}}{\partial \mathrm{t}} .
$$

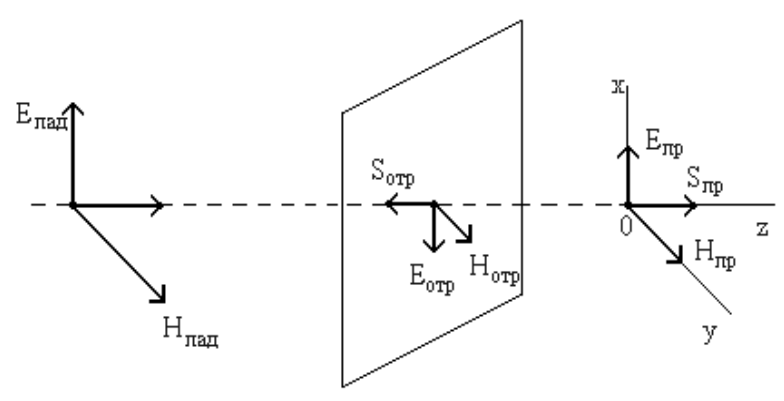

Fig. 1 Penetration of flat electromagnetic wave into the superconducting film

Assume that the electrical and magnetic field stresses change according to sinusoidal law:

$$
\left\{\begin{array}{l}
\mathrm{E}_{\mathrm{x}}=\mathrm{E}_{\mathrm{m}} \sin \left(\omega \mathrm{t}+\varphi_{1}\right), \\
\mathrm{H}_{\mathrm{y}}=\mathrm{H}_{\mathrm{m}} \sin \left(\omega \mathrm{t}+\varphi_{2}\right),
\end{array}\right.
$$

Where $\varphi_{1}$ and $\varphi_{2}$ are the initial phases.

Then the change in the current density and speed of the superconducting charge carriers is proportional to the change in the intensity of the electric field:

$$
\left\{\begin{array}{l}
\mathrm{v}_{\mathrm{S}_{\mathrm{X}}}=\mathrm{v}_{\mathrm{S}_{\mathrm{m}}} \sin \left(\omega \mathrm{t}+\mathrm{f}_{1}\right), \\
\mathrm{H}_{\mathrm{y}}=\mathrm{H}_{\mathrm{m}} \sin \left(\omega \mathrm{t}+\mathrm{f}_{2}\right) .
\end{array}\right.
$$

By presenting the expressions (9) in an indicative form and placing them in equation (7), we have: 


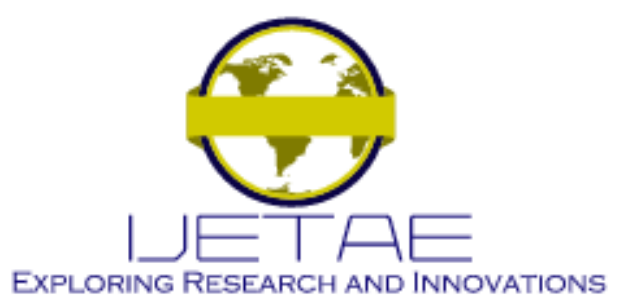

International Journal of Emerging Technology and Advanced Engineering

Website: www.ijetae.com (E-ISSN 2250-2459, Scopus Indexed, ISO 9001:2008 Certified Journal, Volume 11, Issue 07, July 2021)

$$
-\frac{\mathrm{e}}{\mathrm{m}_{\mathrm{S}} \sigma_{\mathrm{N}}} \frac{\mathrm{d} \dot{H}_{\mathrm{m}}}{\mathrm{dz}}=\mathrm{i} \omega \mathrm{v}_{\mathrm{s}_{\mathrm{m}}},
$$

or

$$
\mathrm{v}_{\mathrm{s}_{\mathrm{m}}}=\mathrm{i} \frac{\mathrm{e}}{\mathrm{m}_{\mathrm{S}} \sigma_{\mathrm{N}} \omega} \frac{\mathrm{d} \dot{\mathrm{H}}_{\mathrm{m}}}{\mathrm{dz}} .
$$

The current density of the superconducting charge carriers can then be written as follows:

$$
\mathrm{j}_{\mathrm{S}}=\mathrm{i} \frac{\mathrm{e}^{2} \mathrm{n}_{\mathrm{S}}}{\mathrm{m}_{\mathrm{S}} \sigma_{\mathrm{N}} \omega} \frac{\mathrm{d} \dot{H}_{\mathrm{m}}}{\mathrm{dz}},
$$

Or

$$
\mathrm{j}_{\mathrm{s}}=-\mathrm{i} \frac{1}{\omega \mu_{0} \lambda_{1}^{2}} \dot{\mathrm{E}}_{\mathrm{m}}
$$

Where $\lambda_{1}^{2}=\frac{m_{\mathrm{S}}}{\mathrm{n}_{\mathrm{S}} \mathrm{e}^{2} \mu_{0}}$ is the London penetration depth; $\mu \mathrm{o}$ - magnetic constant.

For charge carriers in the normal state, the current density $\mathrm{j}_{\mathrm{N}}$ can be written based on the first Maxwell equation:

$$
\mathrm{j}_{\mathrm{N}}=\sigma_{\mathrm{N}} \dot{\mathrm{E}}_{\mathrm{m}}
$$

The expressions (12), (13) for $\mathrm{j}_{\mathrm{N}}$ and $\mathrm{j}_{\mathrm{s}}$ are valid for local current-field communication.

To describe the propagation of the wave in a superconducting film, determine the wave resistance $\mathrm{Z}$.

For a wave in a vacuum:

$$
\mathrm{z}_{0}=\sqrt{\frac{\mu_{\mathrm{o}}}{\varepsilon_{\mathrm{o}}}} .
$$

In addition to the conductivity currents $\mathrm{j}_{\mathrm{S}}$ and $\mathrm{j}_{\mathrm{N}}$, there is an offset current $i \omega \varepsilon_{0} \varepsilon_{\mathrm{cp}} \dot{\mathrm{E}}_{\mathrm{m}}$ determined by the dielectric permeability of the medium $\varepsilon_{\mathrm{cp}}$.

The sum of currents (full current) makes it possible to obtain the effective dielectric permeability of the medium:

$$
\varepsilon_{\mathrm{eff}=} \varepsilon_{0} \varepsilon_{\mathrm{cp}} \frac{\sigma}{\mathrm{i} \omega}-\frac{1}{\omega^{2} \mu_{\mathrm{o}} \lambda_{1}^{2}}
$$

Taking into account (14) we shall have:

$$
z=\frac{i \omega \mu_{\mathrm{o}}}{\sqrt{\lambda_{\mathrm{l}}^{-2}+\mathrm{i} \omega \mu_{\mathrm{o}} \sigma_{\mathrm{N}}}},
$$

where $\omega_{0}$ is the EMR frequency.

It is clear that the complex penetration depth is defined as:

$$
\delta^{-2}=\lambda_{1}^{-2}+\mathrm{i} \omega \mu_{0} \sigma_{\mathrm{N}}
$$

Let's rewrite the expression (16) as follows:

$$
\mathrm{Z}=\frac{i \omega \mu_{\mathrm{o}} \lambda_{1}}{\sqrt{\left(1+\frac{\lambda_{1}^{2}}{\delta_{\mathrm{sk}}^{2}} \mathrm{i}\right)^{2}+\frac{\lambda_{1}^{4}}{\delta_{\mathrm{sk}}^{4}}}},
$$

where $\delta_{\mathrm{sk}}=\sqrt{\frac{2}{\omega \mu_{\mathrm{o}} \sigma_{\mathrm{N}}}}$ is the depth of the skin layer.

At $T<T_{c}$ (where $T_{c}$ is the temperature of transition into superconducting state) the condition [7] is generally met:

$$
\lambda_{1}<<\delta_{\mathrm{sk}}
$$

which allows to get the next simple result:

$$
\mathrm{z}=\frac{1}{2}\left(\omega \mu_{\mathrm{o}}\right)^{2} \lambda_{\mathrm{l}}^{3} \sigma_{\mathrm{N}}+\mathrm{i} \omega \mu_{\mathrm{o}} \lambda_{\mathrm{l}} .
$$

At $\mathrm{T}>\mathrm{T}_{\mathrm{c}}$, the strip has only normal conductivity.

Then the basic equations of the electromagnetic field can be written as:

$$
\left\{\begin{array}{l}
\operatorname{rot} \overline{\mathrm{H}}=\sigma_{\mathrm{N}} \overline{\mathrm{E}} \\
\operatorname{rot} \overline{\mathrm{E}}=-\mu_{0} \frac{\partial \overline{\mathrm{H}}}{\partial \mathrm{t}} .
\end{array}\right.
$$

As with superconducting states, let us consider the case where a flat EMW, propagating in dielectric, comes normally to a flat surface restricting superconducting film on one side.

Suppose that both media extend from the partition surface to infinity. 


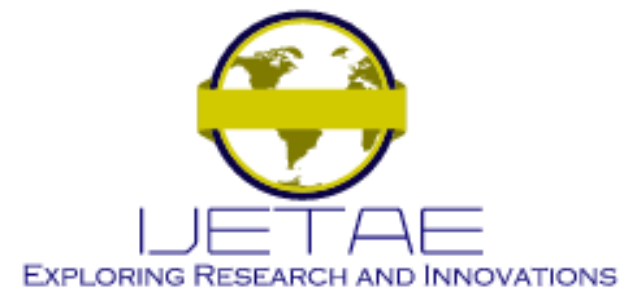

International Journal of Emerging Technology and Advanced Engineering

Website: www.ijetae.com (E-ISSN 2250-2459, Scopus Indexed, ISO 9001:2008 Certified Journal, Volume 11, Issue 07, July 2021)

The incident wave is partly reflected off the superconductor surface, partially penetrated and absorbed into it (see fig. 1).

For a rectangular coordinate system of equation (21) can be written as:

$$
\left\{\begin{array}{l}
\frac{\partial \mathrm{H}_{\mathrm{z}}}{\partial \mathrm{y}}-\frac{\partial \mathrm{H}_{\mathrm{y}}}{\partial \mathrm{z}}=\sigma_{\mathrm{N}} \mathrm{E}_{\mathrm{x}}, \\
\frac{\partial \mathrm{H}_{\mathrm{x}}}{\partial \mathrm{z}}-\frac{\partial \mathrm{H}_{\mathrm{z}}}{\partial \mathrm{y}}=\sigma_{\mathrm{N}} \mathrm{E}_{\mathrm{y}}, \\
\frac{\partial \mathrm{H}_{\mathrm{y}}}{\partial \mathrm{x}}-\frac{\partial \mathrm{H}_{\mathrm{x}}}{\partial \mathrm{y}}=\sigma_{\mathrm{N}} \mathrm{E}_{\mathrm{z}}, \\
\frac{\partial \mathrm{E}_{\mathrm{z}}}{\partial \mathrm{y}}-\frac{\partial \mathrm{E}_{\mathrm{y}}}{\partial \mathrm{z}}=-\mu_{0} \frac{\partial \mathrm{H}_{\mathrm{x}}}{\partial \mathrm{t}}, \\
\frac{\partial \mathrm{E}_{\mathrm{x}}}{\partial \mathrm{z}}-\frac{\partial \mathrm{E}_{\mathrm{z}}}{\partial \mathrm{x}}=-\mu_{0} \frac{\partial \mathrm{H}_{\mathrm{y}}}{\partial \mathrm{t}}, \\
\frac{\partial \mathrm{E}_{\mathrm{y}}}{\partial \mathrm{x}}-\frac{\partial \mathrm{E}_{\mathrm{x}}}{\partial \mathrm{y}}=-\mu_{0} \frac{\partial \mathrm{H}_{\mathrm{z}}}{\partial \mathrm{t}} .
\end{array}\right.
$$

For flat EMW $\overline{\mathrm{E}}$ and $\overline{\mathrm{H}}$ do not depend on $\mathrm{x}$ and $\mathrm{y}$ (see fig. 1), but only on $\mathrm{z}$ and $\mathrm{t}$.

On that basis we shall record:

$$
\frac{\partial \mathrm{H}}{\partial \mathrm{x}}=0, \frac{\partial \mathrm{H}}{\partial \mathrm{y}}=0, \frac{\partial \mathrm{E}}{\partial \mathrm{x}}=0, \frac{\partial \mathrm{E}}{\partial \mathrm{y}}=0, \mathrm{H}_{\mathrm{x}}=0 \text {. }
$$

Then equations (22) can be rewritten as:

$$
\left\{\begin{array}{l}
-\frac{\partial \mathrm{H}_{\mathrm{y}}}{\partial \mathrm{z}}=\sigma_{\mathrm{N}} \mathrm{E}_{\mathrm{x}}, \\
\frac{\partial \mathrm{E}_{\mathrm{x}}}{\partial \mathrm{z}}=-\mu_{0} \frac{\partial \mathrm{H}_{\mathrm{y}}}{\partial \mathrm{t}} .
\end{array}\right.
$$

Equations (23) define EMW in a superconducting film in a normal state.

Assume that the electrical and magnetic field stresses change according to sinusoidal law:

$$
\left\{\begin{array}{l}
\mathrm{E}_{\mathrm{x}}=\mathrm{E}_{\mathrm{m}} \sin \left(\omega \mathrm{t}+\varphi_{1}\right), \\
\mathrm{H}_{\mathrm{y}}=\mathrm{H}_{\mathrm{m}} \sin \left(\omega \mathrm{t}+\varphi_{2}\right) .
\end{array}\right.
$$

By presenting the expressions (24) in a representative form in equation (22) and by making a reduction by a total multiplier $\mathrm{e}^{\mathrm{i} \omega \mathrm{t}}$, we obtain:

$$
\left\{\begin{array}{l}
-\frac{d \dot{H}_{m}}{d z}=\sigma_{N} \dot{E}_{m}, \\
\frac{d \dot{E}_{m}}{d z}=i \omega \mu_{0} \dot{H}_{m} .
\end{array}\right.
$$

By differentiating the first equation in (25) by $\mathrm{z}$ and applying to the right of the obtained equation a value from the second equation is obtained:

$$
\frac{\mathrm{d}^{2} \dot{\mathrm{H}}_{\mathrm{m}}}{\mathrm{dz}^{2}}=\mathrm{i} \omega \mu_{0} \dot{\mathrm{H}}_{\mathrm{m}} .
$$

Equality (26) is a second-order linear differential equation with a constant coefficient whose solution is:

$$
\dot{\mathrm{H}}_{\mathrm{m}}=\mathrm{A}_{1} \mathrm{e}^{-\mathrm{pz}}+\mathrm{A}_{2} \mathrm{e}^{\mathrm{pz}}
$$

where $A_{1}$ and $A_{2}$ are permanent integrations;

$$
\mathrm{p}=\sqrt{\mathrm{i} \omega \mu_{0} \sigma_{\mathrm{N}}} \text {. }
$$

Considering that $\sqrt{\mathrm{i}}=\frac{1}{\sqrt{2}}(1+\mathrm{i})$, the expression (28) can be rewritten as:

$$
p=\sqrt{i \omega \mu_{0} \sigma_{N}}=(1+i) \sqrt{\frac{\omega \mu_{0} \sigma_{N}}{2}} .
$$

A permanent integration of $A_{2}$ can be defined for the following reasons.

If $A_{2} \neq 0$, then with the growth of $z$, as seen in the expression (27), $\dot{H}_{m}$ must increase to infinity.

Since $\dot{H}_{m}$ cannot grow to infinity when EMW is distributed, then, therefore, for physical reasons, there must be $\mathrm{A}_{2}=0$.

Then:

$$
\dot{\mathrm{H}}_{\mathrm{m}}=\mathrm{A}_{1} \mathrm{e}^{-\mathrm{pz}} .
$$




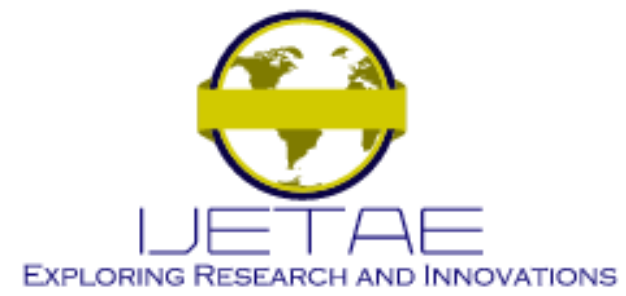

International Journal of Emerging Technology and Advanced Engineering

Website: www.ijetae.com (E-ISSN 2250-2459, Scopus Indexed, ISO 9001:2008 Certified Journal, Volume 11, Issue 07, July 2021)

The integration constant $A_{1}$ can be determined by assuming $\mathrm{z}=0$. In this case $\dot{\mathbf{H}}_{\mathrm{m}}=\mathrm{A}_{1}$, i.e. it has a given value on the surface of the superconductor.

It can therefore be written as:

$$
\mathrm{A}_{1}=\mathrm{He}^{\mathrm{i} \varphi_{20}}=\dot{\mathrm{H}}_{\mathrm{m} 0} .
$$

Thus, the solution of equation (26) will be as follows:

$$
\dot{\mathrm{H}}_{\mathrm{m}}=\dot{\mathrm{H}}_{\mathrm{m} 0 \mathrm{e}^{-\mathrm{pz}}} .
$$

Using the first equation in (25), we obtain an expression for the voltage of the electric field:

$$
\dot{\mathrm{E}}_{\mathrm{m}}=\frac{1}{\sigma_{\mathrm{N}}} \mathrm{p} \dot{\mathrm{H}}_{\mathrm{m} 0} \mathrm{e}^{-\mathrm{pz}} .
$$

The wave resistance of the superconducting film in its normal state can then be determined by taking the relation of $\dot{\mathrm{E}}_{\mathrm{m}}$ to $\dot{\mathrm{H}}_{\mathrm{m}}$ :

$$
\begin{aligned}
& Z_{N}=\frac{\dot{E}_{m}}{\dot{H}_{m}}=\frac{(1+i)}{\sigma_{N}} \sqrt{\frac{\omega \mu_{0} \sigma_{N}}{2}}= \\
& =i \omega \mu_{0} \frac{(1-i)}{2} \sqrt{\frac{2}{\omega \mu_{0} \sigma_{N}}}
\end{aligned}
$$

or

$$
\mathrm{Z}_{\mathrm{N}}=\mathrm{i} \omega \mu_{0} \delta
$$

where, $\delta=\frac{(1-i)}{2} \sqrt{\frac{2}{\omega \mu_{0} \sigma_{N}}}$

or

$$
\delta=\frac{(1-\mathrm{i}) \delta_{\mathrm{sk}}}{2}
$$

This model is valid provided that the EMW frequency does not exceed the critical $\omega_{\text {кр }}$ value, which is determined by the connection energy of the charge carriers at $\mathrm{T}<\mathrm{T}_{\mathrm{c}}$.

2) The analysis of the HTS film parameters necessary for the implementation of the EMR protection device.

If the film is part of an open transmission line, to define a surface film impedance the expression can be formed:

$$
Z=\frac{i \omega \mu_{0} \delta}{\operatorname{th}\left(\frac{h}{\delta}\right)} .
$$

Then, for a superconducting film, based on (20), let's determine the surface impedance:

$$
\mathrm{Z}=\mathrm{i} \omega \mu_{0} \lambda_{\mathrm{l}}\left(1-\frac{1}{2} \mathrm{i} \omega \mu_{0} \sigma_{\mathrm{N}} \lambda_{\mathrm{l}}^{2}\right) \mathrm{F}_{\mathrm{S}}(\mathrm{x}),
$$

where $F_{S}(x)=\frac{\operatorname{sh} 2 x}{\operatorname{ch} 2 x-1}, x=\frac{h}{\lambda_{1}}$,

$\mathrm{h}$ is the thickness of superconducting film.

It should be noted that if the thickness of superconducting film $h$ is commensurate with the penetration depth $\lambda_{1}$, then the film is partially transparent to EMWs, and such film is commonly referred to as thin film.

If we consider that if $\mathrm{h}>\lambda_{1} \operatorname{sh}\left(2 \mathrm{~h} / \lambda_{\mathrm{l}}\right) \approx \operatorname{ch}\left(2 \mathrm{~h} / \lambda_{\mathrm{l}} \lambda_{\mathrm{l}}\right)$ $\gg 1$, and if $\mathrm{h} \ll \lambda_{1} \operatorname{sh}\left(2 \mathrm{~h} / \lambda_{1}\right)$ and $\operatorname{ch}\left(2 \mathrm{~h} / \lambda_{1}\right)$ are decomposed into power series, then we can obtain a reasonably accurate representation of $\mathrm{F}_{\mathrm{s}}(\mathrm{x})$ as [21]:

$$
F_{S}(x)= \begin{cases}\frac{1}{x}, & x \leq 2 \\ 1, & x>2\end{cases}
$$

The approximation error is maximum at $\mathrm{x}=2$ and is $9 \%$.

For the film in normal condition, in accordance with (35) we shall record:

$$
\mathrm{Z}_{\mathrm{N}}=\frac{1}{2} \omega \mu_{\mathrm{o}} \delta_{\mathrm{sk}}(1+\mathrm{i}) \mathrm{F}_{\mathrm{N}}(\mathrm{x}),
$$

where $\delta_{\text {sk }}$ is the thickness of the skin layer,

$F_{N}(x)=\frac{\operatorname{sh} 2 x-i \sin 2 x}{\operatorname{ch} 2 x-\cos 2 x}, x=\frac{h}{\delta_{s k}}$.

In this case we also obtain an approximation formula:

$$
\mathrm{F}_{\mathrm{N}}(\mathrm{x})= \begin{cases}\frac{1-\mathrm{i}}{2 \mathrm{x}}, & \mathrm{x} \leq 1 \\ 1, & \mathrm{x}>1\end{cases}
$$




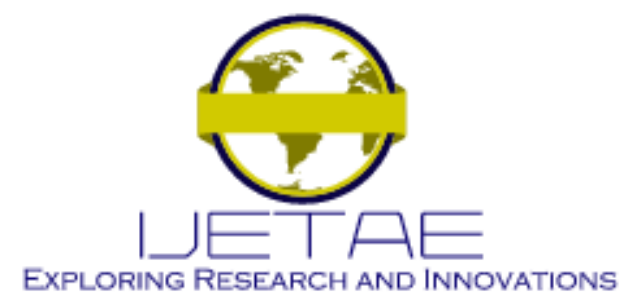

International Journal of Emerging Technology and Advanced Engineering

Website: www.ijetae.com (E-ISSN 2250-2459, Scopus Indexed, ISO 9001:2008 Certified Journal, Volume 11, Issue 07, July 2021)

Error approximating reaches maximum value at $\mathrm{x}=1$ and doesn't exceed $10 \%$.

Let us record the final ratio for the active surface resistance $R$, which is the real part of the surface impedance, and the surface reactive resistance $X$, which is the imaginary part thereof, in superconducting and normal states:

$$
\begin{aligned}
& \mathrm{R}_{\mathrm{S}}=\left\{\begin{array}{l}
\frac{\left(\omega \mu_{\mathrm{O}}\right)^{2} \sigma_{\mathrm{N}} \lambda_{1}^{4}}{2 \mathrm{~h}}, \mathrm{~h} \leq 2 \lambda_{1} \\
\frac{1}{2}\left(\omega \mu_{\mathrm{o}}\right)^{2} \sigma_{\mathrm{N}} \lambda_{1}^{3}, \mathrm{~h}>2 \lambda_{1},
\end{array}\right. \\
& \mathrm{R}_{\mathrm{N}}= \begin{cases}\left(\sigma_{\mathrm{N}} \mathrm{h}\right)^{-1}, & \mathrm{~h} \leq \delta_{\mathrm{sk}} \\
\frac{1}{2} \omega \mu_{\mathrm{o}} \delta_{\mathrm{sk}}, \mathrm{h}>\delta_{\mathrm{sk}},\end{cases} \\
& \mathrm{X}_{\mathrm{S}}=\left\{\begin{array}{l}
\frac{\omega \mu_{\mathrm{o}} \lambda_{1}^{2}}{\mathrm{~h}}, \mathrm{~h} \leq 2 \lambda_{1} \\
\omega \mu_{\mathrm{o}} \lambda_{1}, \quad \mathrm{~h}>2 \lambda_{\mathrm{l}},
\end{array}\right. \\
& \mathrm{X}_{\mathrm{N}}=\left\{\begin{array}{l}
0, \mathrm{~h} \leq \delta_{\mathrm{sk}} \\
\frac{1}{2} \omega \mu_{\mathrm{o}} \delta_{\mathrm{sk}}, \mathrm{h}>\delta_{\mathrm{sk}} .
\end{array}\right.
\end{aligned}
$$

If a superconducting film is used as the basis of a protective device (switch), having two stable states, superconducting and normal, then, in accordance with [22], enter a quality factor $\mathrm{K}$ :

$$
\mathrm{K}=\frac{\left(\mathrm{R}_{1}-\mathrm{R}_{2}\right)^{2}+\left(\mathrm{X}_{1}-\mathrm{X}_{2}\right)^{2}}{\mathrm{R}_{1} \mathrm{R}_{2}},
$$

\section{$\mathrm{K}>>1$,}

where $R_{1}, R_{2}, X_{1}, X_{2}$ are the active and reactive components of the complete resistance of the protective device in two states (superconducting and normal).
This quality parameter is a universal characteristic of switched element in microwave circuits. If a superconducting strip is used as a switchable element capable of being in two states, the K-quality parameter is also its most important characteristic.

As a protective device, consider a superconducting film with length 1 , width $\mathrm{W}(\mathrm{W}<1)$ and thickness $\mathrm{h}$.

Then:

$$
\begin{aligned}
& K=\frac{\left(R_{N}-R_{S}\right)^{2}+\left(X_{N}-X_{S}\right)^{2}}{R_{N} R_{S}}= \\
& =K_{R}+K_{X} .
\end{aligned}
$$

It is obvious that. $\mathrm{R}_{\mathrm{S}}<<\mathrm{R}_{\mathrm{N}}$

In addition, according to equations (41) to (44), $\mathrm{K}_{\mathrm{X}}$ makes a significant contribution only in case of sufficiently thick $\left(\mathrm{h} \geq \lambda_{1}\right)$ superconductor films when $\mathrm{K}$ is below its maximum value. Then the quality parameter can be written as:

$$
\mathrm{K} \approx \mathrm{K}_{\mathrm{R}}=\frac{\mathrm{R}_{\mathrm{N}}}{\mathrm{R}_{\mathrm{S}}}=\frac{1}{2}\left(\frac{\left(\delta_{\mathrm{sk}} / \lambda_{1}\right)^{3}\left(\mathrm{~F}_{\mathrm{N}}\left(\mathrm{h} / \delta_{\mathrm{sk}}\right)\right)}{\mathrm{F}_{\mathrm{S}}\left(\mathrm{h} / \lambda_{1}\right)}\right)
$$

Using approximations (40) and (42), we obtain:

$$
\mathrm{K}_{\mathrm{R}}=\left\{\begin{array}{l}
\frac{1}{4}\left(\delta_{\mathrm{sk}} / \lambda_{\mathrm{l}}\right)^{4}, \mathrm{~h} \leq 2 \lambda_{\mathrm{l}}<<\delta_{\mathrm{sk}} ; \\
\frac{1}{2}\left(\delta_{\mathrm{sk}} / \lambda_{\mathrm{l}}\right)^{3}\left(\delta_{\mathrm{sk}} / \mathrm{h}\right), 2 \lambda_{\mathrm{l}} \leq \mathrm{h} \leq \delta_{\mathrm{sk}} ; \text { (48) } \\
\frac{1}{2}\left(\delta_{\mathrm{sk}} / \lambda_{\mathrm{l}}\right)^{3}, 2 \lambda_{\mathrm{l}}<<\delta_{\mathrm{sk}} \leq \mathrm{h} .
\end{array}\right.
$$

Thus, the highest value of the quality coefficient $\mathrm{K}_{\mathrm{m}}$ is realized when the thickness of the film is less than or equals to penetration depth $\lambda_{1}$ :

$$
\mathrm{K}_{\mathrm{m}} \approx \mathrm{K}_{\mathrm{Rm}}=\frac{1}{4}\left(\delta_{\mathrm{sk}} / \lambda_{\mathrm{l}}\right)^{4} .
$$

In this case, when the film thickness $h$ is reduced, $R_{N}$ and $R_{S}$ grow equally, so $K_{R m}$ does not depend on $h$.

However, it should be noted, that this dependence is only valid if the quality of the film is independent of $h$. 


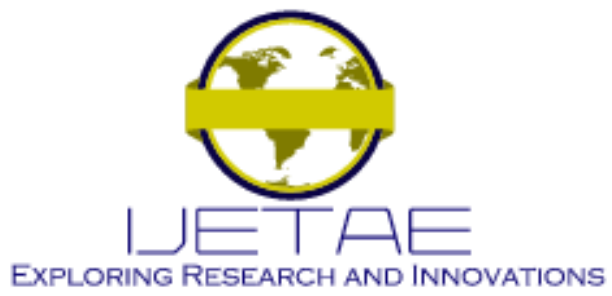

International Journal of Emerging Technology and Advanced Engineering

Website: www.ijetae.com (E-ISSN 2250-2459, Scopus Indexed, ISO 9001:2008 Certified Journal, Volume 11, Issue 07, July 2021)

Films obtained in the real conditions of the existing technology contain defects and are not uniform in thickness. Therefore, by reaching $\mathrm{K}_{\mathrm{Rm}}$ at $\mathrm{h} \approx \lambda_{\mathrm{l}}, \mathrm{K}_{\mathrm{R}}$ can start to decrease at $\mathrm{h}<\lambda_{\mathrm{l}}$. The thickness of the film from which $K_{R}$ becomes less than $K_{R m}$ characterizes the thickness of the defective layer.

\section{RESUlTS AND DISCUSSION}

At $\mathrm{T}<\mathrm{T}_{\mathrm{c}}$, the HTS is at superconducting state. At $\mathrm{T}>$ $\mathrm{T}_{\mathrm{c}}$, the stripe has only normal conductivity. The superconducting state is destroyed provided that the frequency of the EMW does not exceed the critical value $\omega_{\text {кр }}$, which is determined by the connection energy of the charge carriers at $\mathrm{T}<\mathrm{T}_{\mathrm{c}}$. For HTS $\omega_{\text {кр }}=10^{13}-10^{14} \mathrm{c}^{-1}$, that is, it is much higher than the frequency of microwave range.

If the skin layer of the London-wide HTS penetration depth is significantly exceeded, the penetration of the EMW into the superconductor ceases to be frequency dependent and equals the London penetration depth. If the EMW falls on a flat boundary between the free space and the superconductor, and the thickness of the superconducting layer is much larger than the London penetration depth, the surface impedance becomes equal to its wave resistance. In such a case, the superconductor has high critical current values and cannot be used to protect the radio electronic media from a powerful EMR. To implement a protective device based on HTS, the thickness of the film must be consistent with the London penetration depth. In doing so, it is necessary to take into consideration the possible irregularities and defects of the film in order to ensure that the condition of equality of film thickness and penetration depth is met.

Further studies of the use of superconducting films, according to the authors, should be primarily aimed at solving the following priority problems:

1. Investigation of the effectiveness of protective devices based on superconducting films.

2. Development of options for constructing superconducting protective devices based on strip transmission lines.

3. Study of the influence of superconducting protective devices on the passage of working signals.

4. Study of the influence of superconducting protective devices on the passage of powerful electromagnetic pulses through the antenna-feeder path of the receiving device.

\section{CONCLUSION}

1. As a result of studies of the propagation of EMW over the surface of a thin HTS, the basic relations were obtained for determining the value of the surface impedance and the depth of penetration of EMW into a superconducting film in the superconducting $S$ and normal $\mathrm{N}$ states. It is shown that the expression for determining the penetration depth of EMW into a superconducting film in the normal $\mathrm{N}$ state is applicable provided that the frequency of the signal field does not exceed the critical value, which is determined by the binding energy of charge carriers at a temperature not exceeding the transition temperature to the superconducting state.

2. As a result of the analysis of the HTS film parameters required for the implementation of the EMR protection device, a correlation of the HTS on film thickness It is shown that the highest value of the quality coefficient is realized when the thickness of the film is less than or equals the penetration depth. It has been established that this dependence is only valid if the thickness of the film is independent of its quality.

\section{REFERENCES}

[1] Yeromina N., Kurban V., Mykus S., Peredrii O., Voloshchenko O., Kosenko V., Kuzavkov V., Babeliuk O., Derevianko M., Kovalov H. The creation of the database for mobile robots navigation under the conditions of flexible change of flight assignment. International Journal of Emerging Technology and Advanced Engineeri, 11 (5), 2021, pp. 37-44, DOI: 10.46338/ijetae0521_05].

[2] O. Sotnikov, M. Iasechko, V. Larin, O. Ochkurenko, and D.Maksiuta. The model of a medium for creation of electric hermetic screens of the radio electronic means, IJATCSE. 8(2), 2019, pp. 300304. doi:10.30534/IJATCSE/2019/32822019.

[3] O. Vorobiov, V. Savchenko, A. Sotnikov, V. Tarshin, and T. Kurtseitov. Development of radioisotopic-plasmatechnology for the protection of radio electronic means from powerful electromagnetic radiation. Eastern-European Journal of Enterprise Technologies, 5(85), 2017, pp. 16-22. doi:10.15587/1729-4061.2017.91642.

[4] Sotnikov A.M., Kapura I.A., Konyakhin G.F. Metodika opredeleniya parametrov vy`sokotemperaturny`kh sverkhprovodyashhikh SVCh linij peredach s uchetom poverkhnostnogo impedansa Sistemi upravli nnya, navi gaczi yi ta zv'yazku. - Kiyiv: DP "CzNDI NU". - 2010 - Vy`p. SUNZ-3(15). S. 91-93.

[5] Sotnikov A.M., Kapura I.A., Konyakhin G.F. Rezul'taty chislenny'kh raschetov modeli zashhitnogo ustrojstva na osnove vy`sokotemperaturny'kh sverkhprovodnikov. Sistemi upravli`nnya, navi`gaczi`yi ta zv'yazku. - Kiyiv: DP "CzNDI NU". - 2010 - Vip. SUNZ-4(16). - S. 107-111. 


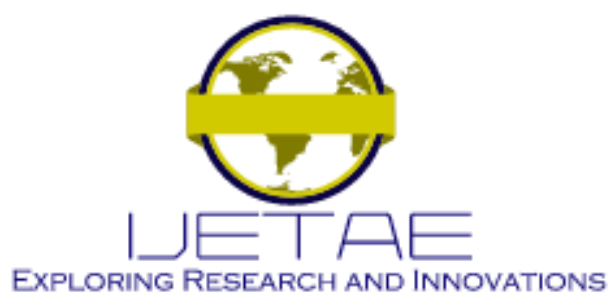

International Journal of Emerging Technology and Advanced Engineering Website: www.ijetae.com (E-ISSN 2250-2459, Scopus Indexed, ISO 9001:2008 Certified Journal, Volume 11, Issue 07, July 2021)

[6] Findikoglu A. T., Jia Q. X., Reagor D. W. Superconductor / Nonlinear-Dielectric Bilayaers for Tunable and Adaptive Microwave Devices // IEEE Transactions on Appl. Supercond. June 1997. Vol. 7. № 2. P. 2925-2928.

[7] Golovkina M.V. Ispolzovanie vyisokotemperaturnyih tonkoplenochnyih sverhprovodnikov dlya sozdaniya upravlyaemyih magnitnyim polem ustroystv. Materialyi VII Mezhdunarodnoy nauchno-tehnicheskoy konferentsii, 7 - 11 dekabrya 2009 g. MOSKVA INTERMATIC - 200 9, chast 2 MIREA str.194-197.

[8] Pal S., Stevens C., Edwards D. A compact, higher order, high temperature superconductor microstrip bandpass filter on a two-inch lanthanum aluminate substrate for personal communication service applications. // Supercond. Sci. Technol. - 2005, v.18, p.1253-1258.

[9] Vendik B., Kondratiev V.V., Kholodniak D.V., Galtchenko S.A., Deleniv A.N., Goubina M.N., Svishchev A.A, Leppavuori S. Hagberg J., Jakku E. High-temperature superconductor filters: modelling and experimental investigations. // IEEE Trans. Appl. Supercond.-1999, v. 9, p.3577-3580.

[10] Remillard S. K., Yi H.R., Abdelmonem A. Three-tone intermodulation distortion generated by superconducting bandpass filters. // IEEE Trans. on Appl. Superconductivity. -2003, v.13, № 3, p.3797-3802.

[11] Yoshida K., Sashiyama K., Nishioka S., Wang Z. Design and performance of miniaturized suparconducing coplanar waveguide filters. // IEEE Trans. on Appl. Superconductivity. -1999, v. 9, № 2, p.3905-3908.]

[12] Kawaguchi, T. Narrowband superconducting receiving filter for 9GHz-band weather radar [Text] / T. Kawaguchi, N. Shiokawa, K. Nakayama, M. Yamazaki, H. Kayano // Proc. of 41st European Microwave Conf., Manchester, UK. - 2011. -P.744-747.
[13] Oudaya Coumar S, Tamilselvan S (2018) Fabrication design of axially rotated square resonator based compact ultrawideband BPF using tight coupling. J Comput Theor Nano Sci 15(5):1695-1699.

[14] Guan X, Le C et al (2019). Compact dual-band HTS band pass flter using coplanar waveguide short-circuited stubloaded ring resonator. IEEE Trans Appl Supercond 29(5), Art. no. 1500704.

[15] Contreras A, Ribo M et al (2018) Compact fully uni-planar band stop flter based on slow-wave multimodal CPW resonators. IEEE Microw Wirel Compon Lett 28(9):780-782.

[16] Elsheikh MAG, Safwat AME (2019) Wide band modeling of SRRloaded coplanar waveguide. IEEE Trans Microw Theory Tech 67(3):851-860.

[17] Semenov A.A., Karmanenko S.F., Melkov A.A., Bobyil A.V., Suris R.A., Galperin Yu.M., Iohansen T.H. Issledovanie potsessa rasprostraneniya poverhnostnoy magnitostaticheskoy volnyi V strukture ferrit/sverhprovodnik,-ZhTF 2001, tom 71, vyip. 10, s. 13 19.

[18] Eremin M.V., Syunyaev D.A. Temperaturnaya zavisimost glubinyi proniknoveniya magnitnogo polya pri nalichii dispersii u parametrov poryadka sverhprovodimosti i voln zaryadovyih plotnostey // Pisma v ZhETF. - 2016. - 10 fevr.- T.103. - Vyip. 3. - S. $209-213$.

[19] Physical properties of high-temperature superconductors. D.M. Ginsberg, M.B. Salamon, A.P. Malozemoff and others: Ed. D.M. Ginsberg. Pe-rev. From English. - M .: Mir, 1990.- 543p.

[20] Davydov A.S. High temperature superconductivity. - K: Naukova Dum-ka, 1990.-176s.

[21] Reviews on High-temperature superconductivity, issue 4(8), 1992.

[22] S. Kawakami. Lossless reciprocal transformation and synthesis of a two-state network. IEEE Trans. on Circuit Theory. 1966. v. ct-13. p. 128-138. 